\title{
6
}

\section{CONSTRUÇÃO DE TEMPO DECORRIDO: USOS NO PORTUGUÊS BRASILEIRO'}

\author{
TIME-ELAPSED CONSTRUCTION: \\ USES IN BRAZILIAN PORTUGUESE
}

\author{
Gabriel Lucas Martins² \\ Universidade Federal do Rio de Janeiro \\ Marcia dos Santos Machado Vieira ${ }^{3}$ \\ Universidade Federal do Rio de Janeiro
}

Resumo: No presente estudo, sob enfoque funcional-cognitivo (BYBEE, 2003; DIESSEL, 2015, WIEDEMER \& MACHADO VIEIRA, 2018; TRAUGOTT \& TROUSDALE, 2013), verificamos ocorrências no Português Brasileiro do fenômeno de alternância de usos de formas linguísticas indicativas de tempo decorrido. Protagonizam essa alternância: a forma de base verbal [há SNtemporal], indicada pela norma padrão, e a forma emergente de base preposicional [a SNtemporal]. Advogamos por uma construcionalização gramatical resultante de uma neoanálise na mente do usuário da língua. A título de comparação, tecemos considerações morfossintáticas sobre outras construções temporais. À luz da concepção da língua como Gramática de Construções, desenhamos possíveis motivações para tal fenômeno. Compõem nosso levantamento de corpus excertos retirados de mídias digitais de junho de 2019, através da coletânea do Corpus do Português.

Palavras-Chave: Gramática de Construções; Construcionalização; Construções de tempo decorrido; Verbo Haver.

1 Artigo desenvolvido a partir de um Trabalho de Conclusão de Curso apresentado ao Curso de Licenciatura em Letras - Português/Inglês, da Universidade Federal do Rio de Janeiro, como requisito parcial à obtenção do título de licenciatura em Português/Inglês.

2 Endereço eletrônico: martinsgl@letras.ufrj.br.

3 Endereço eletrônico: marcia@letras.ufrj.br. 
Abstract: Under a functional-cognitive perspective (BYBEE, 2003; DIESSEL, 2015, WIEDEMER \& MACHADO VIEIRA, 2018; TRAUGOTT \& TROUSDALE, 2013), this study verifies occurrences of alternating linguistic forms to indicate elapsed time in Brazilian Portuguese. The first one is a verb-based form, [há NPtime-indicating], indicated by the standard norm, and the emerging one is a preposition-based form, [a NPtime-indicating]. We advocate for a grammatical constructionalization resulting from a neoanalysis process in the language user's mind. Yet, we propose comparisons between these two constructions and other constructions of time. In lieu of a language conception as a Construction Grammar, we formulate possible motivations for such phenomenon. Our corpus is composed of digital media excerpts from July 2019, retrieved from the online-based cluster, Corpus do Português.

Keywords: Construction Grammar; Constructionalization; Time-elapsed constructions; Verb Haver.

\section{INTRODUÇÃO}

Estudos em torno de 'gramaticalização' e 'lexicalização', juntamente a teorizações sobre 'Gramática Construcional', vêm ganhando foco e novas perspectivas nas últimas décadas. A noção preliminar de gramaticalização como uma (re-)categorização diacrônica de lexemas para morfemas funcionais, por aquisição de funções (mais) gramaticais, é revisitada à luz de uma demanda a que se deu atenção: contexto de uso. A partir disso, tem-se teorizado sobre não ser apenas o elemento 'gramaticizante' submetido ao processo de gramaticalização, mas o elemento gramaticizante no contexto sintagmático. Isto é, a unidade à qual a gramaticalização se aplica é a de construções, não a de itens lexicais isolados (HIMMELMANN, 2004). Por isso, atualmente trata-se dessa questão no escopo do processo de mudança construcional ou construcionalização gramatical. Este gera o pareamento de uma forma ou função nova e resulta numa construção com noção (mais) procedural/funcional. Aquele processo não implica nova construção, mas apenas alteração em construção já existente, ou na sua forma ou no seu funcionamento.

Consequentemente, cogitamos que o fenômeno a ser apresentado pode ser resultado de uma espécie de mescla de um movimento conceptual de analogia 
com a noção de movimento no tempo da forma de base preposicional prospectiva [a $\mathrm{SN}_{\text {temporal] }}$ tempo futuro e um processo de construcionalização, a partir de uma neoanálise de usos de uma construção da língua portuguesa de base verbal ([há

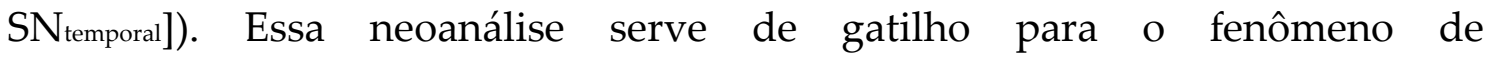
construcionalização gramatical (TRAUGOTT \& TROUSDALE, 2013), que vai gerar uma forma de base preposicional [a $S N_{\text {temporal }}$ tempo decorrido, que se associa a certos atributos discursivos da face funcional do pareamento, atributos estes diferentes dos da forma de base verbal.

No presente estudo, trabalhamos com o verbo haver no âmbito do Português Brasileiro (doravante PB), a partir de instanciações da construção indicativa de tempo decorrido. Avelar (2011) e Móia (2011) argumentam a favor de a estrutura haver + argumento interno já ser empregada como sendo de base gramatical e não oracional nessa construção, ou seja, em que haver assume um papel funcional e não como de verbo (+ semântico). Tal hipótese é atestada através de alguns testes comparativos com construções de sentido semelhante, como a com o verbo ter, como: a possibilidade de clivagem da estrutura com haver; a possibilidade de eliminação da conjunção complementizadora que liga a estrutura a outra oração; e a possibilidade de não-variação modo-temporal do verbo haver quando acoplado a orações no pretérito, como se pode observar em (1) e (2), retirados de Avelar (2011, p. 166):

(1) a. Há duas horas (que) eu vi a Maria no banco.

b. Tem duas horas *(que) eu vi a Maria no banco.

(2) a. Há mais de um mês (que) eu não vejo novela.

b. Tem mais de um mês * (que) eu não vejo novela.

Em Bybee (2003), são introduzidas quatro etapas genéricas à verificação de um processo de gramaticalização, que parafraseamos aqui: (i) redução e/ou adaptação fonética; (ii) sua desconcretização de significado; (iii) aumento na frequência de uso da construção; e (iv) mudança gradual sujeita à variação de 
uso e forma. Em linhas gerais, podemos argumentar que a construção em questão não poderia ter redução fonética, tendo em vista sua simplicidade de forma sonora, /a/, a não ser pelo seu possível enfraquecimento de tonicidade ao anteceder o SN quantitativo de tempo, que desposa de (maior) carga semântica. Em sua tese, Toneli (2009) argumenta que, salvos os complementizadores em contextos específicos, palavras funcionais são formas 'fracas', portanto, clíticos, no que diz respeito aos estudos fonético-fonológicos. No entanto, tal desdobramento de análise tangenciaria os limites dos estudos de prosódia, que não são abarcados nesta pesquisa.

No PB, o verbo haver já não representa muita concreticidade na mente dos falantes. Paiva (2010) corrobora que, desde o século XVII, o verbo vem sendo esvaziado semanticamente, restringindo-se a contextos existenciais, sobretudo na modalidade escrita da língua (p. 26). Quanto à frequência de uso, Avelar (2011) revela um uso ínfimo do verbo haver em comparação a outros de semântica equivalente, como ter. Não obstante, para a construção de tempo decorrido, o autor aponta que o uso de haver (79\%) se mostra muito superior ao de ter $(21 \%)$, até início dos anos 2000, o que alude a um uso específico do verbo haver. Tais condições fomentam o processo de mudança que pretendemos captar neste estudo.

Portanto, a construção de tempo decorrido com o verbo haver (doravante CTD-haver) pode estar sob o efeito priming (DIESSEL, 2015), em que ela é cognitivamente associada à outra construção com semelhanças estruturais e/ou semânticas. Diessel (2015) aponta que tal efeito é crucial ao desenvolvimento gramatical e pode culminar num processo indicado por Traugott \& Trousdale (2013) como sanção/sancionamento, que indica uma 'mesclagem' dos esquemas das construções. A CTD-haver estaria sendo sancionada ao esquema da construção gramatical com a preposição $a$ (doravante CTD-a). 
Para corroborar os estudos anteriores e tentar conceber melhor essa mudança, este trabalho introduz corpora que se faziam ausentes até então a este caso. Nos excertos sob análise aqui, podemos interpretar uma manifestação morfológica dessa vacilação de análise estrutural do falante ou um mero epifenômeno dos chamados erros de grafia, galgado pelos efeitos dos meios de comunicação da contemporaneidade e suas especificidades linguísticas. Essas possíveis visões serão mais bem destrinchadas no próximo ponto.

\section{PROBLEMAS, OBJETIVOS E HIPÓTESES DE TRABALHO SOB OLHAR CONSTRUCIONISTA}

É preciso considerar inicialmente que os usos em análise aqui podem estar atrelados a um emaranhado de fatores. Primeiramente, não é incomum encontrar palavras com grafia incongruente com a norma padrão em mídias digitais, tendo em vista que elas geralmente propiciam ambientes de comunicação de pouco monitoramento e mais próximos da espontaneidade das interações face a face. Portanto, existe também a possibilidade de os casos em foco neste estudo serem resultantes de um mero descuido na produção escrita. Além disso, é um ambiente aberto aos mais variados estratos sociais, níveis de escolaridade e faixas etárias. Portanto, as mídias digitais são propícias a abrigar falares diversos, incluindo aqueles mais distantes da norma padrão. Por fim, podemos pesar, ainda, a possibilidade de ser indício de uma mudança construcional ou construcionalização gramatical em curso, nossa hipótese de trabalho.

A princípio, nossa hipótese gira em torno de um novo link ter surgido na mente dos usuários da língua e estar gradativamente sendo fortificado, entre a então CTD-haver e outras construções temporais encabeçadas por preposição. Em verdade, há uma construção temporal de tempo futuro que faz uso da 
preposição $a$, e que poderia estar sendo assimilada à CTD-haver. A título de ilustração dessa possibilidade, tomemos por base o exemplo a seguir:

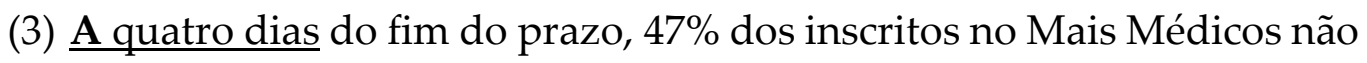
se apresentaram (O Globo, 2018)

Em (3) podemos observar o uso de uma construção de identificação de intervalo de tempo por meio de prospectividade. Esse uso assemelha-se ao uso em (4), distinguindo-se apenas no que diz respeito à perspectiva temporal das construções. Observemos:

(4) Pompeo anunciou há um ano 12 condições para concluir um "novo acordo", em particular restrições ao programa nuclear iraniano e uma redução das atividades regionais do Irã. (O Globo, 2019)

Ambos os casos são indicativos de intervalo temporal: em (3) há indicação de um intervalo de tempo entre o momento da enunciação e um evento futuro, e em (4) há indicação de um intervalo de tempo entre um evento passado e o momento da enunciação. Portanto, o que os difere é a perspectiva temporal. Móia (2011) chama atenção inclusive para o fato de que ambas construções em outras línguas, como o inglês, por exemplo, são comumente constituídas de uma preposição e um SN quantitativo de tempo.

Ainda, Móia atentou para um outro subdomínio de significação da CTDhaver, que seria o dos exemplos (5-6), de duração ancorada, i. e., a duração de um evento que teve início em um momento passado e perdura até o momento de enunciação ou até um outro momento, indicado na oração por meio de uma outra construção temporal.

(5) Treinando há um ano e meio, ela sonha em participar da equipe de Jundiaí e, um dia, transformar o esporte em profissão. (Jornal da Região, 2019)

(6) Estou a um ano e meio livre, sem bebidas e drogas. (Diário de Petrópolis, 2019) 
Também a este subdomínio de significação da CTD-haver, é comum em outras línguas o uso de uma preposição no lugar em que empregamos o verbo haver (em inglês, por exemplo, a preposição for desempenharia o papel do verbo haver). Portanto, há indícios bastante plausíveis para pensarmos que os falantes do PB possam estar reinterpretando a estrutura dessa construção.

Em consonância, em pesquisa por dicionários, Paiva (2010) se depara com obras que argumentam em favor da "expressão temporal" formada com verbo haver configurar um elemento adverbial que pode inclusive modificar o verbo da outra oração. Para Fernandes (1958), trata-se de uma oração adverbial. Já Almeida (2008) argumenta que o verbo haver é percebido como preposição por analogia com outras expressões temporais. Almeida defende ainda que o uso de atrás ou quaisquer outras palavras que enfatizem tempo decorrido configuram redundância, pois a presença de haver já daria cabo desse sentido. No entanto, o usuário comum da língua parece não enxergar essa redundância, justamente porque para ele o verbo haver está esvaziado de sentido.

Por conseguinte, o principal objetivo deste estudo é tentar determinar a real natureza desse fenômeno: se é uma mera discordância da norma padrão generalizada nos meios digitais, se é resultado de uma mudança (construcional ou construcionalização gramatical) ou se é uma associação dos dois casos em concomitância, fomentando um ao outro.

Não obstante, nosso estudo requer também a verificação de um pareamento dessas construções com aquelas compostas pelos verbos ter e fazer, também indicativas de tempo decorrido. Precisamos considerar as relações estabelecidas entre estas construções. Enquanto os verbos haver e ter são bastante análogos nesta construção, sendo ambos impessoais e estáticos, o verbo fazer distancia-se deles pela dinamicidade inerente ao seu valor semântico. Entretanto, nos cabe averiguar se o verbo haver ainda é interpretado pelo usuário da língua como não-dinâmico. A preposição $a$ pressupõe movimento e naturalmente 
carrega o traço de dinamicidade e, mesmo que os usuários não cheguem às últimas consequências de grafar a construção com "a" em lugar de "há", o surgimento da CDT-a pode evidenciar que eles a interpretam como uma estrutura dinâmica.

\section{EMBASAMENTO TEÓRICO-METODOLÓGICO}

À luz de uma abordagem baseada no uso, o conceito de construcionalização é aqui discutido no campo da Gramática de Construções. Nessa perspectiva teórica, a unidade mínima de análise é a construção, "uma unidade simbólica em que são pareados forma (fonético-fonológica, morfossintática, lexical) e significado/função (semântica, discursiva, pragmática, social e cognitiva)" (WIEDEMER; MACHADO VIEIRA, 2018, p. 87). De acordo com Wiedemer \& Machado Vieira (2018), um dos preceitos do modelo baseado no uso é que a experiência com a língua constrói e afeta representações cognitivas da língua, e que essas representações são codificadas e categorizadas de acordo com forma fonética, significado e contexto. Em consonância com esta teoria, argumentamos aqui a favor do fenômeno de neoanálise de uma construção, resultando em exemplares que permitem o processo de construcionalização da CTD-haver.

Ao conceber a língua como Gramática de Construções, assumimos que o sistema linguístico se organiza em nós, que são padrões construcionais (com diferentes níveis de esquematicidade/abstração) que constituem os recursos linguísticos e seus modos de organização, determinando a forma da materialização linguística (WIEDEMER; MACHADO VIEIRA, 2018). Diante desta perspectiva, como Traugott \& Trousdale (2013) apontam, o fenômeno de construcionalização envolve formação de novos links entre os nós na mente do usuário, mas nenhum nó novo é adicionado à rede de padrões construcionais (p. 
46). Os autores explicam que o fenômeno se inicia a partir da produção de um novo construto advindo de um pensamento analógico. Caso esse construto venha a ser compartilhado por uma comunidade de usuários e comece a ocorrer com repetição e convencionalização, pode resultar em uma neoanálise.

Destarte, refletindo sobre o pensamento analógico ao qual usuários podem estar submetidos, há outras construções de interesse para este estudo. Avelar (2011) e Móia (2011) reconhecem outras estruturas usadas para indicar o mesmo sentido que analisamos na CTD-haver/ CTD-a. Para citar algumas, Avelar (2011) recorda-nos de verbos como fazer, completar, passar e dar que podem construir significado de tempo decorrido quando acoplados a um sintagma nominal que indique uma medida ou um montante temporal. Não obstante, ele argumenta que os verbos mais proeminentes para indicar tal noção são haver e ter, respectivamente, que são "parte de um mesmo paradigma sintático-lexical na história do português" (p. 163). Machado Vieira (2008), em estudo sociolinguístico sobre a alternância de haver, ter ou fazer na expressão de tempo decorrido, também sinaliza emprego expressivo de haver, seguido de ter, nas variedades brasileira e portuguesa. Portanto, haver, ter e fazer são os verbos que consideraremos neste estudo, a despeito de comparações semântico-sintáticas.

Com base em Sinha \& Bernárdez (2015), entendemos que tempo é cognitivamente concebido em relação ao domínio do espaço e é psicologicamente mensurável, bem como dualmente mapeado a partir do espaço da enunciação. $\mathrm{O}$ tempo-espaço da predicação emerge a partir de uma perspectivação dele como tempo-cenário e, assim, em certa medida estático/estacionado (acionando-se a forma de base verbal, verbo haver de estado), ou como tempo-objeto em movimento através de um espaço-cenário para trás/tempo corrido ou tempo a correr ou para frente/tempo vindouro (acionando-se a forma de base preposicional). Não é à toa que se recorre, nas expressões de tempo decorrido, ao lexema "atrás". O mapeamento da experiência do tempo depende da experiência 
corpórea dos indivíduos/observadores a partir de uma orientação frente-trás. $\mathrm{O}$ futuro está adiante do observador e o passado está atrás do observador. O observador/a enunciação é o centro dêitico dessa orientação. E os eventos são localizados no tempo, assim como no espaço ocupado pelos participantes envolvidos no evento, e conceitualizados com propriedades de duração ou de sucessão. Nossa navegação no espaço é realizada na mente e manifestada no discurso linguístico. Tempo-sucessão é posicional em significado dentro da linha do tempo. Tempo-duração é interpretado como relativo a movimento espacial, passagem, ou seja, extensão temporal.

As Metáforas de "passagem" podem, mas não precisam, envolver o uso explícito de verbos de movimento, tais como vir, ir, passar, chegar e assim por diante; em vez disso, elas podem ter sua interpretação metafórica em locuções adverbiais como "o próximo ano", e podem ser estativas e de orientação, bem como dinâmicas, por vezes envolvendo movimento fictício. (TALMY, 1999 apud SINHA; BERNÁRDEZ, 2015, p. 64)

Finalmente, além de conceitos e pressupostos da Linguística FuncionalCognitiva, esta pesquisa também está ancorada em algumas teorizações da Linguística Textual, no tangente ao trabalho com gêneros do discurso. Em consonância com essa abordagem, lidamos aqui com dados retirados de contextos reais de uso, ao entender que "o sentido de um texto não existe a priori, mas é construído na interação sujeito-texto" e "assim sendo, na e para a produção de sentido, necessário se faz levar em conta o contexto" (KOCH; ELIAS, 2018, p. 57, grifo das autoras). Ainda, entendemos que cada enunciado é individual, mas que cada contexto de uso suscita "tipos relativamente estáveis de enunciados, os quais denominamos gêneros do discurso" (BAKHTIN, 2016, p. 262). Portanto, dispomos estes textos dentro de uma delimitação discursiva, considerando dois gêneros principais na amostra de dados: (i) artigo de notícia/de opinião e (ii) comentário na web. Por fim, sublinhamos uma importante distinção destes dois gêneros, feita por Bakhtin (1953/1979 apud SCHNEUWLY, 2011), que seria sua 
complexidade discursiva. $O$ artigo de notícia/de opinião seria um gênero secundário, mais complexo discursivamente, resultado de uma produção cultural mais bem desenvolvida e relativamente mais evoluída. Enquanto o comentário na web se enquadraria no que Bakhtin denomina gênero primário, fruto de uma comunicação verbal espontânea e menos elaborada (SCHNEUWLY, 2011). A importância de tais considerações ficará mais evidente no decorrer de nossa metodologia.

\section{METODOLOGIA}

Para esta pesquisa, recolhemos dados do Corpus do Português, organizado por Mark Davies. O acervo selecionado para recolhimento dos dados foi o NOW Corpus (<https://www.corpusdoportugues.org/now/>), cujo corpus é criado a partir do reconhecimento digital de URLs de artigos de revistas e jornais digitais disponíveis no Google News. Para nossa análise, foi feito um levantamento de 470 tokens de diferentes textos datados do mês de junho de 2019. Os dados foram analisados com dois grupamentos em mente: (I) Comparativo Dual entre CTD-haver e CTD-a; e (II) Comparativo Múltiplo entre CTD-haver, CTD-a, CTD-ter e CTD-fazer. E cada grupamento foi analisado sobre dois clines de especificidade temporal do SN: um de noção imprecisa de tempo [_ muito tempo] e outro de noção precisa de tempo [_ um ano].

A noção de precisão e imprecisão temporal das construções ocorre num continuum e não há como averiguarmos graus de precisão temporal específicos. Portanto, elencamos os SNs quantitativos especificados acima, considerando-os usos rotineiros para noções mais ou menos precisas de tempo decorrido.

Para refinar a análise dos tokens, eles foram subdivididos ainda em três contextos linguístico-discursivos (A, B e C). E para cada um destes contextos, separamos os usos feitos pelo grupo editorial da página digital e os usos feitos 
por internautas comuns, configurando, então, ou o gênero secundário artigo (de notícia ou de opinião) ou o gênero primário comentário na web. Os contextos linguístico-discursivos foram discriminados entre:

A. Artigo de Conteúdo Político / Econômico;

B. Artigo de Conteúdo Esportivo e de Entretenimento (Tabloide); e

C. Artigo de Notícia / Opinião Geral.

Ainda, os tokens foram analisados quanto à natureza de seus discursos, considerando que, de acordo com a carga emotiva do discurso, este poderia sofrer consequências quanto à adesão ou não à norma padrão. Portanto, consideramos os dois tipos genéricos de discurso: D1) Objetivo; e D2) Subjetivo. A distinção básica entre os dois tipos de discurso idealizados foi feita a partir da identificação da(s) sequência(s) tipológica(s) empregada(s) em cada trecho estudado. Marcuschi (2008) apresenta seis sequências linguísticas que podem se manifestar em um texto: narração, argumentação, exposição, descrição e injunção (p. 154-155). A partir da prevalência de uma sequência no trecho, delimitamos sua natureza como mais objetiva (narrativa e descritiva) ou mais subjetiva (argumentativa, expositiva e injuntiva).

Em alguns casos, a CTD manifestou-se em falas reportadas através de discurso direto, comum a artigos de notícia. A escrita, nesses casos, é de autoria de um (profissional de um) grupo editorial, mas a natureza do discurso (objetiva ou subjetiva) será determinada pela fala original, que estiver sendo reportada. Portanto, mesmo que se trate de um trecho de uma notícia que adote sequências tipológicas mais objetivas, caso a fala reportada esteja imbuída de carga passional, atravessando sequências tipológicas mais subjetivas, o token é analisado como subjetivo.

Por fim, a título de comparar a funcionalidade das CTDs com a de estruturas adjuntas adverbiais, decidimos analisar o posicionamento mais usual em que a CTD-haver e a CTD-a se encontram nos períodos coletados. A partir 
disso, observações de ordem morfossintática podem ser desenhadas. Com base na proposta de Martelotta (1994), estipulamos seis posições possíveis ao adjunto adverbial:

Quadro 1 - Posição de adjunto adverbial

\begin{tabular}{|l|l|}
\hline \multicolumn{1}{|c|}{ Antes do Verbo } & \multicolumn{1}{c|}{ Depois do Verbo } \\
\hline (a) sem sujeito & (d) sem complemento \\
\hline (b) antes do sujeito & (e) entre o verbo e o complemento / predicativo \\
\hline (c) entre o sujeito e o verbo & (f) depois do complemento / predicativo \\
\hline
\end{tabular}

Fonte: Martelotta (1994 apud PAIVA, 2010, p. 88).

Além destas, Paiva (2010) reconhece outras três posições para expressões temporais com haver: (g) em relação a um nome, antes do nome; (h) em relação a um nome, depois do nome; e (i) "complementando" um verbo (p. 90).

Em suma, cada token foi, então, codificado quanto (I) ao elemento predicador da construção (verbos haver, ter, fazer ou a preposição a); (II) ao conteúdo temático (A, B ou C); (III) à autoria do enunciado (Redação editorial ou Internauta); (IV) à natureza do discurso (D1 ou D2); e (V) à posição da CTD no período ( $a, b, c, d, e, f, g, h$ ou i). Com isso, pudemos realizar análises quantitativas para determinar a frequência de uso das formas analisadas (há, $a$, tem e faz), bem como os contextos semântico-morfossintáticos que aparentam propiciar o uso de cada forma.

Ainda, a fim de tecer breves considerações sobre outras configurações possíveis às construções em foco, [haver $\mathrm{SN}_{\text {temporal }}$ e [a $\mathrm{SN}_{\text {temporal }}$, verificamos a

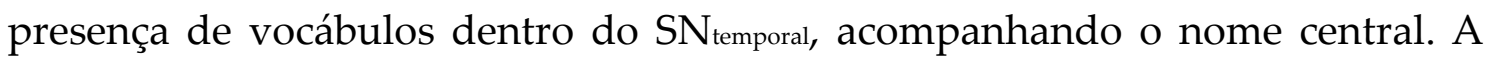
partir dos tokens coletados e de sua análise, delineamos quatro funções de vocábulos que podem ocorrer dentro do SN temporal (modificador, intensificador, quantificador e angulador). Desdobramentos dessas considerações serão comentados na próxima seção. 
Ao final do recolhimento e codificação dos dados de acordo com as variáveis estabelecidas, obtivemos o seguinte cenário de distribuição de uso das construções pelos três contextos linguístico-discursivos e pelas autorias de seus textos, registrado na Tabela 1 abaixo:

Tabela 1 - Distribuição dos dados por autoria e contexto linguístico-discursivo

\begin{tabular}{|c|c|c|c|}
\hline \multicolumn{4}{|c|}{ Distribuição dos dados por autoria e contexto linguístico-discursivo } \\
\hline & A & B & C \\
\hline Redação Editorial & 106 & 151 & 198 \\
\hline Internautas Comuns & 7 & 4 & 4 \\
\hline
\end{tabular}

Como esperado, a vasta maioria de dados manifestou-se em textos produzidos por um grupo editorial ou profissional da área de jornalismo. Na Tabela 2 abaixo, visualizamos a proporção expressa por cada CTD em cada contexto linguístico-discursivo, com indicação precisa de suas porcentagens no montante total. Com esses dados, percebemos o que fora constatado por estudos anteriormente citados (AVELAR, 2011; PAIVA, 2010), que, para indicação de tempo decorrido, a expressão com o verbo haver é consideravelmente mais usada que as demais. Não obstante, apesar de os usos com a preposição $a$ não terem obtido porcentagens tão expressivas, chegaram a ultrapassar em mais de duas vezes os usos com o verbo ter e a atingir cerca de $1 / 3$ dos usos encontrados para o verbo fazer.

A Tabela 2 registra a proporção dos dados pelos contextos linguísticodiscursivos estabelecidos. Como percebemos, a distribuição das ocorrências pelos contextos revelou-se relativamente homogênea, possibilitando $o$ levantamento mais preciso de hipóteses quanto às manifestações morfossintáticas presumivelmente propiciadas por cada contexto. Observa-se 
ainda que a porcentagem de CTDs-fazer (6,22\%) tornou-se muito superior à de CTDs-ter (0,84\%), se comparadas aos valores encontrados por Machado Vieira (2008), de 7\% para fazer e 11\% para ter. A diminuição da proporção de uso da CTD-ter e a aparente manutenção da proporção de uso da CTD-fazer podem corroborar uma mudança da perspectiva que usuários da língua conferem ao tempo (como dinâmico, e não estático), que exploraremos mais adiante.

Tabela 2 - Distribuição das CTDs por contexto linguístico-discursivo

\begin{tabular}{|c|c|c|c|c|}
\hline \multicolumn{5}{|c|}{ Distribuição das CTDs por contexto linguístico-discursivo (em \%) } \\
\hline & A & B & C & TOTAL \\
\hline CTDs-haver & $105(22,3 \%)$ & $137(29,1 \%)$ & $185(39,4 \%)$ & $427(90,8 \%)$ \\
\hline CTDs-a & $6(1,3 \%)$ & $3(0,63 \%)$ & $1(0,21 \%)$ & $10(2,14 \%)$ \\
\hline CTDs-ter & $\varnothing(0 \%)$ & $1(0,21 \%)$ & $3(0,63 \%)$ & $4(0,84 \%)$ \\
\hline CTDs-fazer & $2(0,42 \%)$ & $14(3 \%)$ & $13(2,8 \%)$ & $29(6,22 \%)$ \\
\hline
\end{tabular}

Como vemos na Tabela 3, o contexto linguístico-discursivo com mais dados é o C, o que já era esperado dado sua menor restrição temática. Enquanto A e B são contextos mais limitados tematicamente (política/economia e esportes/entretenimento, respectivamente), C inclui notícias de assuntos gerais. A princípio, essa divisão buscava averiguar a hipótese de que os assuntos abordados nos contextos A e B propiciaram enunciados mais passionais. E de fato, eles se mostraram os contextos com mais discursos subjetivos (tipo D2), enquanto o contexto C abrigou a maior parte dos discursos objetivos (tipo D1). E, como ainda abordaremos adiante, a natureza dos discursos se revelou realmente significativa para o uso de algumas CTDs em lugar de outras. 
Tabela 3 - Produtividade de D1/D2 nos contextos linguístico-discursivos

Produtividade de D1/D2 nos contextos linguístico-discursivos (em val. absolutos)

\begin{tabular}{|c|c|c|c|c|}
\hline & A & B & C & TOTAL \\
\hline D1 & 75 & 88 & 169 & 332 \\
\hline D2 & 37 & 67 & 33 & 137 \\
\hline
\end{tabular}

Em seguida, ao isolar a variável natureza do discurso, percebemos que, para as CTDs verbais, houve mais ocorrências no tipo 1 de discurso, enquanto, para a CTD preposicional, as ocorrências no tipo 2 excederam as do tipo 1 em 90\% (Tabela 4). Considerando D1 como aquele mais objetivo, assumimos que a maioria dos casos envolvem meios de maior monitoramento. Em contrapartida, D2 seria aquele mais subjetivo, possivelmente aplicado em contextos de menor monitoramento e consequentemente de menor proximidade com a norma padrão da língua. Não obstante, é relevante notar que ainda assim houve um caso de CTD-a num trecho tipificado como D1. E ainda, três dos usos da CTD-a tipificados como D2 foram encontrados em textos redigidos pelo grupo editorial responsável pelo website de onde o texto foi retirado. Esses casos podem corroborar a hipótese de estar surgindo uma adoção bastante sutil dessa nova forma, CTD-a (em lugar da CTD-haver), mesmo em contextos mais inesperados.

Tabela 4 - Distribuição de cada CTD pela natureza do discurso

\begin{tabular}{|c|c|c|}
\hline Distribuição de cada CTD pela natureza do discurso (em valores absolutos) \\
\hline & D1 & D2 \\
\hline CTDs-haver & 313 & 114 \\
\hline CTDs-a & 1 & 9 \\
\hline CTDs-ter & 2 & 2 \\
\hline CTDs-fazer & 17 & 12 \\
\hline
\end{tabular}


Por fim, o Gráfico 1 abaixo expõe as posições sintáticas em que as CTDs se manifestaram nos dados coletados, com base no Quadro 1 e demais contribuições de Paiva (2010). Para os predicadores verbais ter e fazer, a posição sintática mais proeminente foi (b) antes do sujeito. Por se tratar de predicadores verbais, as expressões temporais que formam têm valor de oração, portanto é comum que ocupem uma posição de oração. Havendo uma relação de subordinação entre as orações, as posições mais comuns a elas seriam as de justaposição à margem esquerda ou direita uma da outra, com interligação do conectivo que, como foi o caso, sobretudo com o verbo fazer. Pelo fato de a CTD-ter e a CTD-fazer figurarem orações principais, é comum que antecedam suas subordinadas. Ainda, como formam orações usualmente mais enxutas, é natural também que elas obedeçam ao princípio de peso final (end weight), que prevê "que constituintes menores e menos complexos precedem constituintes maiores e mais complexos, ou, em outros termos, que a periferia direita da oração é o site preferencial de constituintes mais pesados" (PAIVA, 2012, p. 30).

Gráfico 1 - Comparação da distribuição de posições sintáticas para cada CTD

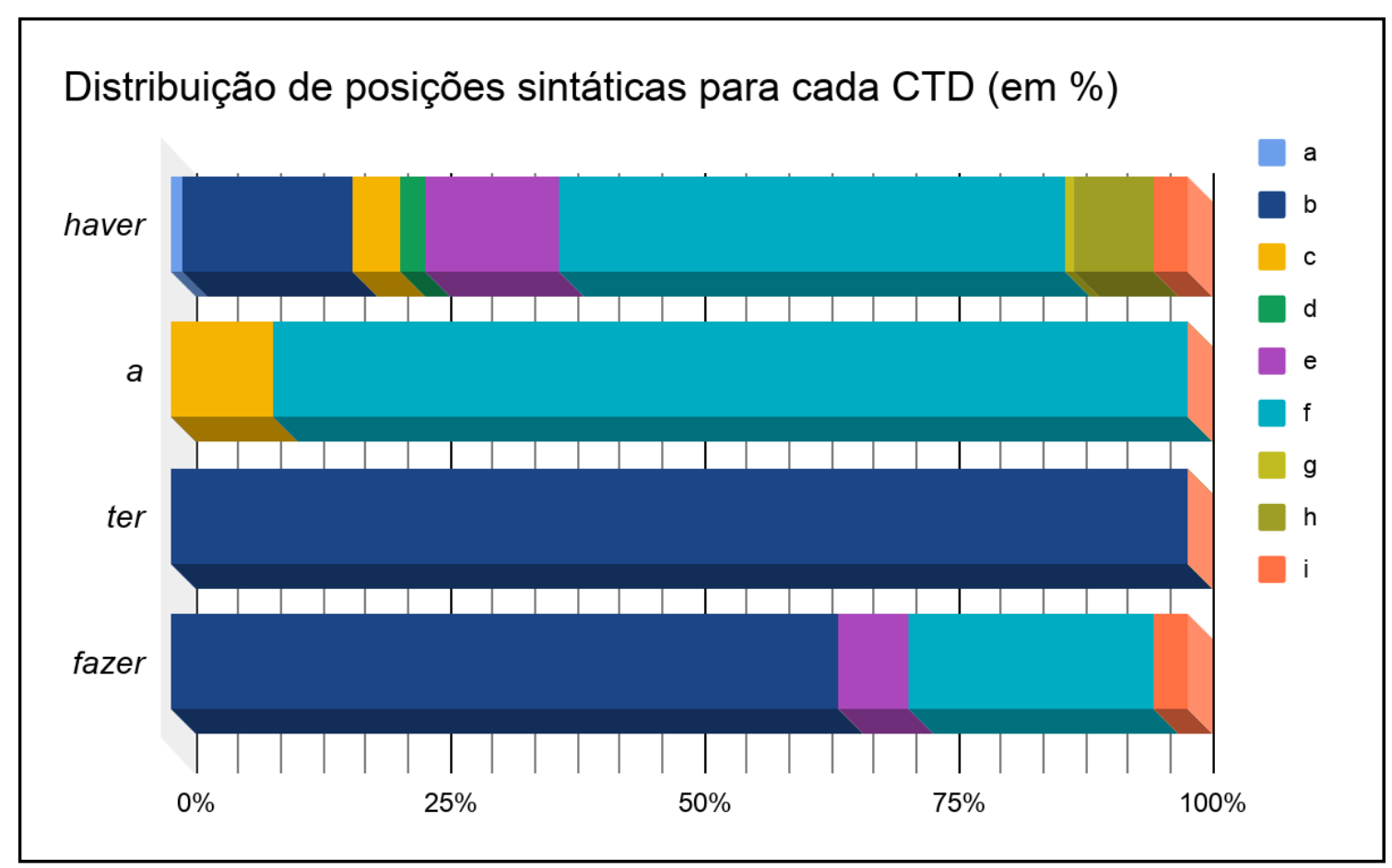


Em contrapartida, as formas com verbo haver e com a preposição $a$ (apesar dos poucos dados gerais) apresentaram números consideravelmente maiores de usos na posição (f) depois do complemento/predicativo. Não obstante, é sensato salientar que tanto esta quanto as figurações sintáticas (a) sem sujeito, (b) antes do sujeito e (d) sem complemento seriam típicas de SPreps temporais, embora a literatura corrobore que posições à esquerda da oração sejam mais usuais (PAIVA, 2008, p. 73-74). Os posicionamentos em relação a verbo (c) entre o sujeito e o verbo, (d) sem complemento, (e) entre o verbo e o complemento/predicativo e (i) "complementando" um verbo e os em relação ao nome $(\mathrm{g})$ antes do nome e $(\mathrm{h})$ depois do nome não apresentaram quantidade expressiva de manifestação.

O estudo de Soares \& Cezario (2012) sobre as posições de SPreps condicionais temporais em textos jornalísticos apresenta resultados bastante equilibrados de manifestações de SPreps temporais em ambas as margens da oração (40,6\% na margem esquerda e 39,1\% na margem direita). As autoras apontam ainda que a preferência por uma margem em lugar da outra está comumente atrelada à fluidez do texto, estabelecendo referentes espaciais e temporais dentro e entre parágrafos, e à ênfase que se pode querer dar ou não ao SPrep (SOARES; CEZARIO, 2012, p. 232-233).

Finalmente, para registros mais precisos, em valores absolutos, a Tabela 5 expõe a quantidade de casos de cada CTD nas posições estabelecidas por Paiva (2010). Mais uma vez fica notável a prevalência da CTD-haver em comparação às demais, ao atentarmos dessa vez, não só para a valor total muito superior de casos de CTD-haver, como também para o fato de que esta é a única construção que se manifesta em todas as posições consideradas. Isso pode ser indicativo de dois fatores: (i) que os usos da CTD-haver vacilam entre os típicos de uma estrutura verbal e os típicos da estrutura de um SPrep; e (ii) que a proeminência de seu uso em detrimento do uso das demais CTDs naturalmente possibilita aplicações mais variadas, incluindo as menos usuais. O primeiro fator pode ser 
alusivo a uma amálgama de interpretações morfossintáticas que ainda prevalece sobre o verbo haver nesta construção. Isto é, os usuários da língua podem estar fazendo usos ora mais oracionais, ora mais nominais da construção. O segundo fator, apesar de não aludir a esta hipótese, pode contribuir para sua concretização. Isso quer dizer que o fato de a CTD-haver permitir outras manifestações morfossintáticas pode facilitar reinterpretações de seu papel sintático pelo usuário da língua.

Tabela 5 - Distribuição das posições sintáticas para cada CTD

\begin{tabular}{|c|c|c|c|c|c|c|c|c|c|}
\hline \multicolumn{2}{|c|}{ Distribuição das posições sintáticas para cada CTD (em valores absolutos) } \\
\hline & $\mathbf{a}$ & $\mathbf{b}$ & $\mathbf{c}$ & $\mathbf{d}$ & $\mathbf{e}$ & $\mathbf{f}$ & $\mathbf{g}$ & $\mathbf{h}$ & $\mathbf{i}$ \\
\hline CTDs-haver & 5 & 71 & 20 & 11 & 56 & 212 & 4 & 34 & 14 \\
\hline CTDs-a & $\varnothing$ & $\varnothing$ & 1 & $\varnothing$ & $\varnothing$ & 9 & $\varnothing$ & $\varnothing$ & $\varnothing$ \\
\hline CTDs-ter & $\varnothing$ & 4 & $\varnothing$ & $\varnothing$ & $\varnothing$ & $\varnothing$ & $\varnothing$ & $\varnothing$ & $\varnothing$ \\
\hline CTDs-fazer & $\varnothing$ & 19 & $\varnothing$ & $\varnothing$ & 2 & 7 & $\varnothing$ & $\varnothing$ & 1 \\
\hline
\end{tabular}

Por fim, debrucemo-nos brevemente na questão de alguns elementos eventualmente integrantes das CTDs. A partir das observações feitas das instanciações das construções analisadas, delineamos quatro funções de vocábulos que podem ocorrer dentro do SN temporal (modificador, intensificador, quantificador e angulador). No Quadro 2 abaixo, dispomos as funções identificadas, com exemplos de classes gramaticais que podem desempenhar tais funções e de vocábulos que se enquadram nessas classes.

Quadro 2 - Possíveis integrantes satélites das CTDs

\begin{tabular}{|l|l|}
\hline Modificador & - Adjetivo: atrás* \\
\hline Intensificador & $\begin{array}{l}\text { - Advérbio: muito, bastante } \\
\text { - Palavra denotativa: mesmo }\end{array}$ \\
\hline Quantificador & $\begin{array}{l}\text { - Numeral: um, meio } \\
\text { - Pronome indefinido: alguns, poucos, vários, muitos } \\
\text { - Locução adverbial: (pouco) mais de, (pouco) menos de }\end{array}$ \\
\hline Angulador & - Advérbio: já, exatamente, quase \\
\hline
\end{tabular}

Fonte: Elaborado pelos autores. 
Observamos que os anguladores, "palavras (verbos, locuções prepositivas e adverbiais, adjetivos) que têm em comum, do ponto de vista semântico, o fato de introduzirem taxa de flexibilização expressiva ao item escopado, produzindo sua reconceptualização" (ALMEIDA, 1999, p. 129-130), além de poderem integrar o SNtemporal, podem também modificar toda a construção como um elemento satélite seu, antecedendo-a ou sucedendo-a. Observemos um exemplo abaixo:

(7) Exatamente há um ano, em 20 de junho de 2018, em João Pessoa e Campina Grande outro meteoro foi registrado. (O Povo, 2019)

Tirando o modificador atrás, os demais elementos elencados no Quadro 2 acima são facilmente encontrados em todas as CTDs, embora esta pesquisa não tenha feito um levantamento preciso de suas proporções, com indicação dos vocábulos mais proeminentes para cada CTD, pois isso fugiria ao escopo de nosso objetivo central. No entanto, a produtividade do modificador atrás nas CTD-haver e CTD-a é bastante significativa para as hipóteses desta pesquisa.

Em verdade, o adjetivo atrás poderia ser enquadrado como intensificador, pois ele dá ênfase à perspectiva temporal de passado. Porém, tomamos a liberdade de considerar o papel desse adjetivo nas construções como de um modificador, pois ele já se faz um integrante quase cativo da construção, aludindo a uma perda de entendimento dela como essencialmente referente ao passado. Isto é, a concreticidade semântica do verbo haver nessa construção está desmantelando-se na mente do usuário comum da língua, contrariando o que Almeida (2008, apud PAIVA, 2010, p. 29) defende ser um uso redundante. O que para o autor figuraria uma espécie de elemento pleonástico, passa a ser interpretado pelo usuário comum da língua como um elemento quase indispensável à CTD.

Ainda, o uso da palavra atrás reforça a ideia de que o usuário da língua se posiciona temporalmente a partir de categorias cognitivas metafóricas na associação de espaço-tempo, assumindo, portanto, um caráter dinâmico à 
construção, independentemente de como se dê a sua grafia. Isto é, apesar dos usos de CTD-haver ainda serem consideravelmente superiores aos de CTD-a ao menos no corpus aqui estudado - o fato de usuários vacilarem no uso do intensificador/modificador - como queira considerar - atrás nos leva a ponderar que eles atribuem à construção um caráter de dinamicidade.

Cabe-nos, nesse sentido, considerar implicações relativas à metáfora conceptual de espaço-tempo naturalmente presente na interpretação cognitiva dessas construções, por conta de seu traço [+/- dinâmico]. Conforme já apontado por Sinha \& Bernárdez (2015), a noção espacial é tida como principal fonte/domínio de origem para estruturação linguística e conceitual de tempo. Ao tratarmos de usos da CTD-a, o entendimento de dinamicidade está impregnado na semântica desta construção, fazendo com que o usuário comum da língua assuma, em seu enunciado, que a construção pressupõe, então, um movimento temporal retrospectivo. À preposição $a$ - por regra uma preposição (de deslocamento) espacial - é atribuída uma noção de deslocamento temporal. Por fim, considere a Figura 1 abaixo, em que propomos uma representação das relações estabelecidas entre as construções levantadas neste estudo. 
Figura 1 - Relações esquemáticas entre as CTDecorrido (CTDs) e a CTProspectivo (CTP) na marcação de tempo

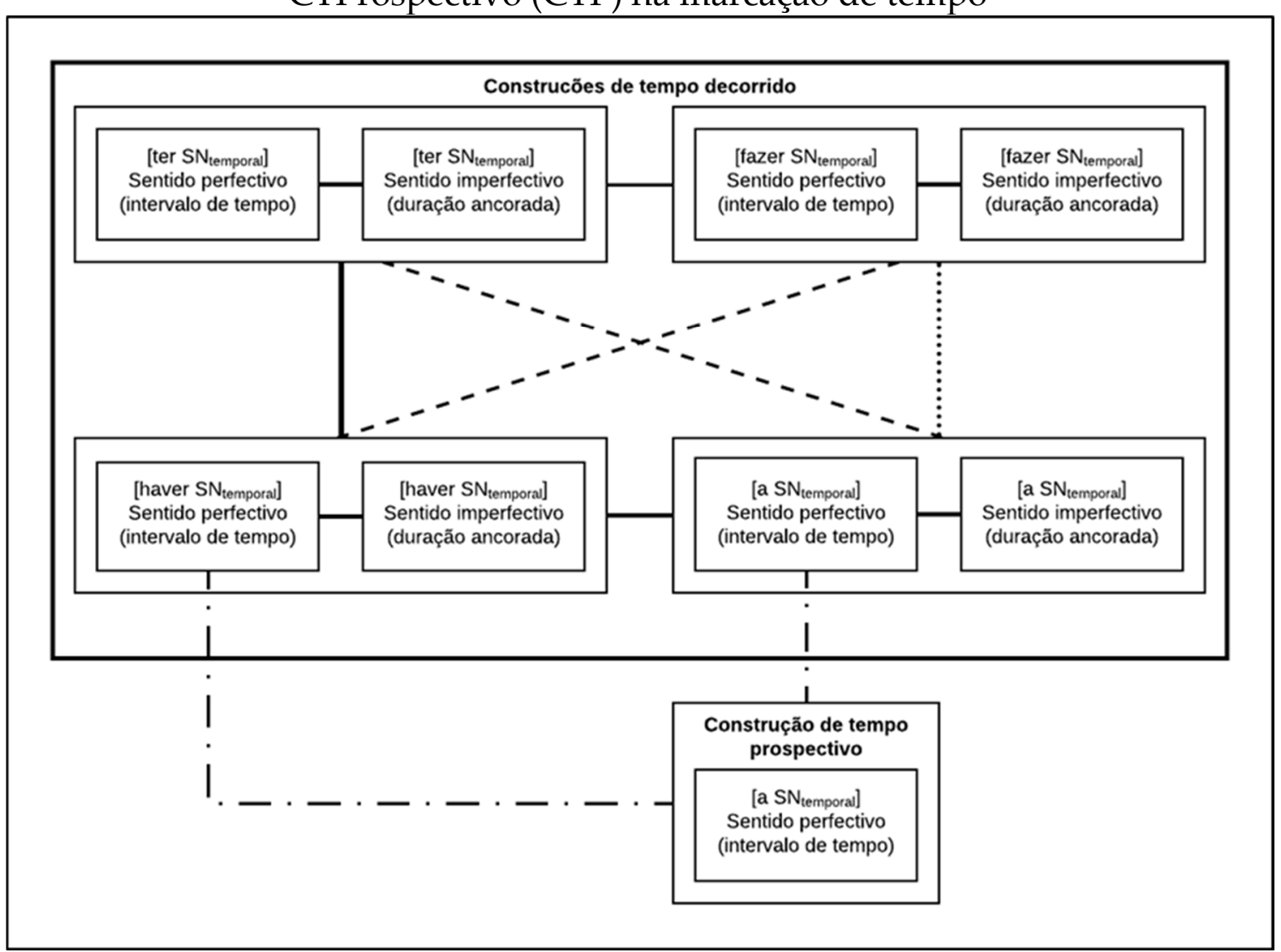

Fonte: Elaborado pelos autores.

A figura acima busca ilustrar as relações estabelecidas entre as CTDs estudadas nesta pesquisa. A princípio, temos quadrantes de cada CTD com dois sentidos possíveis, um perfectivo, que indica intervalo temporal, e outro imperfectivo, que indica duração temporal ancorada ${ }^{4}$. A partir de seu valor semântico (de significado), morfológico (de forma) e sintático (de função), bem como de seu caráter [+/- dinâmico], cada CTD estabelece links de relação com as demais CTDs. Percebam que as quatro estão relacionadas de alguma maneira, pois são todas construções de indicação temporal. A distinção de força dos tipos de links estabelecidos entre cada pareamento se dá: (i) pela sua base

4 Conforme já conceituado aqui através do estudo de Móia (2011), em que o autor aponta duas significações possíveis para os usos da CTD-haver: (i) uma que indica um intervalo temporal entre um evento passado e o momento da enunciação; e (ii) uma que indica a duração de um evento iniciado no passado e que perdura até o momento da enunciação. Para relembrar como cada sentido pode se manifestar, refira-se novamente aos exemplos (3-6). 
verbal/preposicional; (ii) pelo caráter estático/dinâmico que cada forma pressupõe; e (iii) pela perspectiva temporal de cada construção. A partir disso, se estabelece a noção de metaconstrução (WIEDEMER; MACHADO VIEIRA, 2018), um espaço de neutralização das diferenças entre os padrões construcionais de base verbal e os de base preposicional, representado no retângulo maior da figura, em prol de variantes construcionais para sinalização de tempo decorrido.

As formas verbais ter e haver possuem um link mais forte entre si, tal qual as formas verbal e preposicional fazer e $a$, pois as primeiras são tradicionalmente estáticas, enquanto as duas últimas são dinâmicas. Não obstante, já foi aqui considerado, mais de uma vez, que a forma haver está sendo associada a um uso mais dinâmico, o que provavelmente é uma motivação para o surgimento da construção de base preposicional [a $\mathrm{SN}_{\text {temporal }}$ com valor de tempo decorrido. Portanto, poderíamos supor/projetar, em pouco tempo, um quadro que representasse o link entre haver e ter mais enfraquecido, ao passo que o link de haver com $a$ se fortificaria cada vez mais, até poder resultar num desuso da CTDhaver, dando lugar à CTD-a majoritariamente/exclusivamente. Por fim, não se pode esquecer do link estabelecido entre as formas de sentido perfectivo CTDhaver, CTD-a e CTP-a. Como já comentado anteriormente, a dinamicidade acometida aos usos de haver nessa construção e inerente à preposição $a$ permitem uma associação da CTD-haver e da CTD-a com a construção de tempo prospectivo CTP-a. Dessa forma, confirmamos que o usuário comum está passando a interpretar a CTD-haver/CTD-a, não como um referente temporal (perspectivado como paralítico) com estrutura subordinante/subordinado de uma outra oração, mas tal qual um sintagma preposicional adjunto adverbial que desloca temporalmente o enunciado em que se apresenta, ressaltando seu traço de dinamicidade. 


\section{CONSIDERAÇÕES FINAIS}

Com este estudo, observamos que podemos flagrar uma possível reconfiguração estrutural, neoanálise, da CTD-haver para uma CTD-a, que amalgamaria não apenas duração acoplada e identificação de intervalo temporal por mediação retrospectiva, mas também a identificação de movimento envolvida no intervalo temporal por mediação prospectiva. Dessa forma, o usuário da língua aparenta estar reinterpretando o sentido da construção, a partir de uma metáfora conceptual de espaço-tempo, ao conferir um caráter mais dinâmico à estrutura, que se manifesta seja no uso do lexema atrás (com ambas CTD-haver e CTD-a), seja no próprio emprego da CTD-a, em que a preposição $a$ já é indicativa de um caráter dinâmico.

A partir disso, poderíamos arriscar um indicativo do progressivo desuso do verbo haver na variedade do PB. Além de já reduzidos, alguns usos deste verbo vinculam-se a construções impessoais pouco familiares ao falante comum. Este verbo, que já se resume a usos ditos formais do $\mathrm{PB}$, aparentando ter pouca concreticidade na mente do falante, talvez diminua sua frequência na língua, se estivermos de fato captando um fenômeno de construcionalização gramatical desse verbo em indicações de tempo decorrido. E, mesmo que ainda seja usado, sua categorização cognitiva na mente do usuário já não aparenta mais ser como de base verbal e sim preposicional.

Apesar de nosso foco pousar no PB, não podemos ignorar que no PE o verbo haver ainda aparenta ter maior frequência de uso, quando comparamos ambas variedades, como Avelar (2011) menciona. Portanto, questões de ordem histórico-político-cultural teriam que ser visitadas se quisermos pensar num plausível desuso desse verbo em qualquer que seja a variedade do português. Apesar de o Brasil acomodar a maior parte dos falantes de português, estaríamos 
lidando com fatores de ordem extralinguística ao pensar no futuro morfossintático de um verbo dessa língua.

Sublinhamos aqui que, apesar de podermos estar tratando de um caso de padrão construcional gerado por construcionalização gramatical, não se tem como traçar ainda sua natureza. Tendo em vista os acordos existentes entre os países lusófonos de manutenção de certas normas mútuas, bem como a dificuldade em se moldar qualquer cânone gramatical pelas inúmeras razões político-econômicas envolvidas nisso, a inclusão de uma CTD-a na norma padrão talvez seja utópica. Não obstante, poderia haver uma concessão partitiva: a norma brasileira poderia conceber ambas CTD-a e CTD-haver como possíveis formulações indicativas de tempo decorrido, tanto para significações de duração ancorada como de intervalo temporal retrospectivo, como apontadas por Móia (2011).

Decerto, ainda caminhamos em um solo bastante desconhecido, cujos impactos não podemos prever bem. Por isso, este estudo pede por continuidade. Acreditamos que algo desta sorte ainda seja muito novo aos olhos da linguística. Creio que dos dois lados do Atlântico, inclusive, tais pesquisas se devam engendrar, a fim de apurarmos nossa acepção desta possível reanálise estrutural por parte dos luso-falantes. Devemos pensar que, no tangente à CTD-haver, ambas as variedades europeia e brasileira aparentam ter semelhanças suficientes para cogitarmos uma co-neoanálise estrutural, a qual seria propícia à natureza da construção em si e não a um grupo de falantes específico.

\section{REFERÊNCIAS}

ALMEIDA, M. L. L. de. Processo de mesclagem em anguladores no português do Brasil. In: Veredas - revista de estudos linguísticos. Vol. 3, n. 1. Juiz de Fora: EDUFJF, p. 129-142, jan./jun. 1999.

ALMEIDA, Napoleão M. de. Dicionário de questões vernáculas. São Paulo: Ática, 2008. 
AVELAR, J. Expressões de tempo decorrente com ter e haver na fala carioca. Diadorim. Rio de Janeiro, Vol. 8, p. 161-180, 2011.

BAKHTIN, M. Os gêneros do discurso. Paulo Bezerra (Organização, Tradução, Posfácio e Notas); Notas da edição russa: Seguei Botcharov. São Paulo: Editora 34, 2016.

BYBEE, J. Cognitive processes in grammaticalization. In: The new psychology of language: Cognitive and functional approaches to language structure. Mahwah, NJ: Erlbaum, Vol. 2, p. 145-167, 2003.

DIESSEL, H. Usage-based construction grammar. In: DABROWSKA, E.; DIVJAK, D. (eds.). Handbook of Cognitive Linguistics. Berlin: Mouton de Gruyter, p. 295-321, 2015.

FERNANDES, Francisco. Dicionário de verbos e regimes. 4./42. Ed. São Paulo: Globo, 1958 [1940].

HIMMELMANN, N. Lexicalization and grammaticalization: Opposite or orthogonal? In: BISANG, W.; HIMMELMANN, N. P.; WIEMER, B. (eds.) What makes grammaticalization? A look from its fringes and its components. Berlin: Mouton de Gruyter, p. 21-42, 2004.

KOCH, I.; ELIAS, V. Ler e compreender: os sentidos do texto. $3^{a}$ ed., $13^{a}$ reimpressão. São Paulo: Contexto, 2018.

WIEDEMER, M.; MACHADO VIEIRA, M. Lexemas e construção: atração, coerção e variação. Caderno Seminal Digital Especial, n. 1, Vol. 1, p. 81-132, 2018.

MACHADO VIEIRA, M. Haver, ter ou fazer na expressão de tempo decorrido. In: RONCARATI, C.; ABRAÇADO, Jussara. Português Brasileiro II: contato linguístico, heterogeneidade e história. Niterói: EdUFF, p. 192-202, 2008.

MARCUSCHI, L. Gêneros Textuais no Ensino de Língua. In: Produção Textual, Análise de Gêneros e Compreensão. $1^{a}$ ed., 11ª reimpressão. São Paulo: Parábola Editorial, p. 154-155, 2008.

MARTELOTTA, Mário E. Os Circunstanciadores Temporais e sua Ordenação: uma visão funcional. Tese de Doutorado em Linguística - Faculdade de Letras, UFRJ, Rio de Janeiro, 1994.

MÓIA, T. Expressões Temporais com Haver: Gramaticalização e Interpretação Semântica. In: COSTA, Armanda; FALÉ, Isabel; BARBOSA, Pilar (eds.), XXVI Encontro Nacional da Associação Portuguesa de Linguística: Textos seleccionados. Lisboa: Associação Portuguesa de Linguística, p. 401-419, 2011.

PAIVA, Maíra S. D. Há muito tempo atrás: Um estudo sobre HAVER + nome com valor temporal. Dissertação (Mestrado em Letras Vernáculas) - Faculdade de Letras, UFRJ, Rio de Janeiro, 2010.

PAIVA, Maria D. C. D. Ordem relativa de circunstanciais no português brasileiro escrito. Revista Diacrítica, n. 22/1, dia 73, p. 73-91, 2008.

PAIVA, Maria D. C. D. Restrições à posição de Spreps temporais na modalidade falada. Alfa, revista linguística (São José Rio Preto), São Paulo, Vol. 56, n. 1, p. 29-53, 2012. 
SCHNEUWLY, Bernard. Gêneros e Tipos de Discurso: Considerações Psicológicas e Ontogenéticas. In: SCHNEUWLY, Bernard; DOLZ, Joaquim. Gêneros Orais e Escritos na Escola. 3a ed. Campinas: Mercado de Letras, p. 19-34, 2011.

SINHA, C.; BERNÁRDEZ, E. Espaço, tempo e espaço-tempo: metáforas, mapas e fusões. Revista Brasileira de Linguística Antropológica, Vol. 7, n. 1, julho de 2015.

SOARES, B.; CEZARIO, M. Ordem de sintagmas preposicionais com valor temporal em textos jornalísticos. Revista Diacrítica, n. 26/1, p. 226-247, 2012.

TONELI, Priscila Marques. A palavra prosódica no português brasileiro: o estatuto prosódico das palavras funcionais. Dissertação (Mestrado em Linguística) - Instituto de Estudos da Linguagem, Universidade Estadual de Campinas, Campinas, 2009. Disponível em: <http://repositorio.unicamp.br/jspui/handle/REPOSIP/270913>. Data de acesso: 20 de novembro de 2020.

TRAUGOTT, E.; TROUSDALE, G. Cap. 2: A Usage-Based Approach to Sign Change. In: Constructionalization and constructional changes. Oxford: Oxford University Press, Vol. 6, p. 45-93, 2013.

Nota do editor:

Artigo submetido para avaliação em: 11 de julho de 2020.

Aprovado em sistema duplo cego em: 11 de novembro de 2020. 